\title{
PENGARUH KEDISIPLINAN TERHADAP \\ KEPUASAN KERJA PEGAWAI \\ (STUDI PEGAWAI POLITEKNIK ILMU PELAYARAN SEMARANG)
}

\author{
Janny Adriani Djari ${ }^{a}$, Firdaus Sitepu ${ }^{b}$ \\ a dan ${ }^{b}$ Dosen Program Studi Nautika PIP Semarang
}

\begin{abstract}
The purpose of this study to examine the effect discipline by job satisfaction of employees in Seamanship Polytechnic Semarang. Under these conditions, this study took the title "The Effect of Discipline Against by Employee Job Satisfaction (Study of Employee Seamanship Polytechnic Semarang)"

In this study took the population in this study were employees of the Polytechnic Semarang Seamanship, amounting to 218 persons. Sampling with random sampling technique that randomly sampling 142 respondents.
\end{abstract}

Based on the research that has been done it is known discipline effect on job satisfaction.

\section{Keywords: influence of discipline, employee discipline, job satisfaction}

\section{PENDAHULUAN}

\section{A. Latar Belakang Masalah}

Upaya untuk mencapai kepuasan pegawai diantaranya dengan memperhatikan kedisiplinan kerja pegawai. Kedisiplinan adalah setiap perseorangan dan juga kelompok yang menjamin adanya kepatuhan terhadap perintah dan berinisiatif untuk melakukan suatu tindakan yang diperlukan seandainya tidak ada perintah (Heidjrachman dan Husnan, 2002). Sikap mental pegawai perlu dibina secara terus menerus, karena dengan tumbuh kembangnya sikap mental disiplin akan sangat membantu organisasi / perusahaan dalam pencapaian tujuan yang maksimal. Kedisiplinan pegawai dapat terwujud apabila peraturan-peraturan perusahaan yang ada tidak terlalu mengekang gerak dan langkah pegawai dalam melaksanakan pekerjaannya. Pegawai yang mampu mendisiplinkan diri dalam bekerja akan memberikan manfaat kepada dirinya sendiri disamping organisasi / perusahaan. Mereka akan aman dalam bekerja, kebutuhan terpenuhi, tercapainya standar dan target organisasi / perusahaan, suasana kerja yang harmonis, nyaman, kesejahteraan tercapai dan tujuan organisasi / perusahaan tercapai tanpa adanya masalah.

Dengan kedisiplinan yang tinggi akan menimbulkan kepuasan kerja pegawai.
Kepuasan kerja menguraikan suatu hal positif yang dirasakan di sekitar pekerjaan, sebagai hasil suatu evaluasi tentang karakteristik pekerjaan. Seseorang dengan kepuasan kerja yang lebih tinggi akan merasakan hal yang positif di sekitar pekerjaannya, seorang yang tidak puas akan merasakan hal yang negatif (Robbins, 2006). Kepuasan kerja mempunyai peran penting dalam mendukung komitmen organisasional karyawan serta dapat merangsang semangat kerja. Walaupun suatu hubungan kuat antara kepuasan dan komitmen organisasional telah ditemukan, riset terakhir memberi lebih dalam mendukung kepada gagasan dimana kepuasan penyebab komitmen organsiasional.

Kajian penelitian mengenai pengaruh kedisiplinan terhadap kepuasan kerja pegawai akan dilakukan pada pegawai di Politeknik Ilmu Pelayaran Semarang. Politeknik Ilmu Pelayaran Semarang adalah salah satu Lembaga Pendidikan Maritim negeri dibawah naungan Kementerian Perhubungan dan satusatunya yang berada di Jawa Tengah, yang berlokasi di Jalan Singosari 2A Semarang dengan tugas pokok membina dan mencetak lulusan perwira-perwira kapal niaga, baik kapal-kapal milik negara maupun kapal-kapal swasta. 


\section{B. Perumusan Masalah}

Berdasarkan latar belakang yang menunjukkan permasalahan penelitian, maka permasalahan dalam penelitian ini adalah "Bagaimana pengaruh kedisiplinan terhadap kepuasan kerja di Politeknik Ilmu Pelayaran Semarang ?". Agar pembahasan masalah dalam penelitian lebih jelas, maka perlu adanya perumusan masalah secara sistematis sebagai berikut: "Bagaimana pengaruh kedisiplinan terhadap kepuasan kerja Pegawai Politeknik Ilmu Pelayaran Semarang ?"

\section{Pembatasan Masalah}

Untuk menghindari luasnya ruang lingkup materi yang dibahas, maka penulis memberikan batasan masalah pada pengaruh kedisiplinan terhadap kepuasan kerja pegawai di Politeknik Ilmu Pelayaran Semarang.

\section{Tujuan Penelitian}

Adapun tujuan penelitian ini adalah "Untuk menguji dan menganalisis pengaruh kedisiplinan terhadap kepuasan kerja Pegawai Politeknik Ilmu Pelayaran Semarang"

\section{E. Manfaat Penelitian}

Adapun manfaat yang dapat diambil dari penelitian ini adalah:

1. Manfaat Akademik

Hasil penelitian ini diharapkan dapat menjadi sumbangan pengetahuan dan bahan pertimbangan bagi pihak lain yang membutuhkan, bila ingin mempelajari masalah-masalah yang ada hubungannya dengan pengaruh kedisiplinan terhadap kepuasan kerja pegawai.

2. Manfaat Manajerial

Merupakan masukan yang dapat dipertimbangkan oleh pimpinan dalam menentukan kebijaksanaan khususnya di bidang personalia tentang kedisiplinan, dan kepuasan kerja pegawai.

\section{TINJAUAN PUSTAKA}

\section{Pengembangan Hipotesis}

$\mathrm{H}$ : Kedisiplinan berpengaruh terhadap kepuasan kerja.

\section{Kerangka Pemikiran Teoritis}

Keadaan yang ideal dalam perusahaan adalah apabila perusahaan memperoleh manfaat yang maksimal dari para karyawannya dalam pencapaian tujuan perusahaan, demikian juga para karyawan dapat memenuhi kebutuhan sesuai dengan peranannya. Beberapa upaya untuk mencapai keadaan tersebut dengan kedisiplinan yang tinggi maka akan menciptakan kepuasan kerja pegawai yang tinggi terhadap instansi kerja. Berdasarkan uraian tersebut di atas maka dapat disusun kerangka teoritis sebagai berikut:

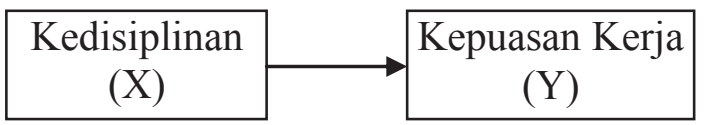

Gambar Kerangka Model Penelitian

\section{METODE PENELITIAN}

\section{A. Populasi Penelitian}

Populasi menurut Sutrisno Hadi (2001) adalah sekumpulan dari seluruh elemenelemen yang dalam hal ini diartikan sebagai obyek penelitian. Adapun populasi dalam penelitian ini adalah dosen dan keryawan Politeknik Ilmu Pelyaran Semarang yang berjumlah 218 orang.

\section{B. Sampel Penelitian}

Sampel adalah sebagian atau wakil populasi yang akan diteliti (Sutrisno Hadi, 2001). Sampel dalam penelitian ini adalah pegawai Politeknik Ilmu Pelayaran Semarang. Pengambilan sampel dengan teknik random sampling yang merupakan teknik pengambilan sampel secara acak. Untuk penentuan jumlah sampel berdasarkan pendapat Umar (2002) yang menyatakan jumlah sampel minimal 30 pada kebanyakan penelitian sudah terwakili. Oleh sebab itu penentuan jumlah sampel digunakan rumus slovin diperoleh 142 responden.

\section{Jenis dan Sumber Data}

Dalam penelitian ini menggunakan data primer. Data primer merupakan data yang bersumber dari tangan pertama, data yang diambil menggunakan cara kuesioner. Kuesioner merupakan daftar pertanyaan 
Janny Adriani Djari ${ }^{\mathrm{a}}$, Firdaus Sitepu ${ }^{\mathrm{b}}$

yang dipakai sebagai pedoman untuk mengadakan tanya jawab dengan responden mengenai pengaruh kedisiplinan terhadap kepuasan kerja pegawai di Politeknik Ilmu Pelayaran Semarang.

\section{Uji Instrumen Penelitian}

\section{Uji Validitas}

Uji validitas digunakan untuk mengukur valid tidaknya suatu indikator yang berbentuk kuesioner. Suatu kuesioner dikatakan valid jika pertanyaan mampu untuk mengungkapkan suatu yang akan diukur oleh kuesioner tersebut. Dalam penelitian ini, uji validitas menggunakan analisis faktor yaitu dengan menguji apakah butir-butir indikator atau kuesioner yang digunakan dapat mengkonfirmasikan sebuah faktor atau konstruk. Jika masing-masing pertanyaan merupakan indikator pengukur maka memiliki KMO diatas 0,5 dan memiliki nilai kriteria loading faktor pengujian sebagai berikut (Singgih Santoso, 2000):

- Loading faktor $>$ rule of tumb $(0,4)$ berarti valid

- Loading faktor < rule of tumb $(0,4)$ berarti tidak valid

2. Uji Reliabilitas

Suatu alat ukur instrumen disebut reliabel, jika alat tersebut dalam mengukur segala sesuatu pada waktu berlainan, menunjukkan hasil yang relatif sama. Pengukuran reliabilitas dapat dilakukan dengan koefisien Alpha Cronbach menggunakan SPSS For Windows (Singgih Santoso, 2000 ) dengan kriteria:

- Bila nilai alpha > 0,6 maka instrumen reliabel

- Bila nilai alpha $<0,6$ maka instrumen tidak reliabel

\section{E. Analisis Regresi Berganda}

Suatu analisa yang digunakan untuk mengetahui persamaan regresi yang menunjukkan persamaan antara variabel dependent dan variabel independent dengan rumus sebagai berikut:

$$
\mathrm{Y}=\mathrm{a}+\beta \mathrm{X}+\mathrm{e}
$$

$$
\begin{aligned}
& \text { Keterangan: } \\
& \mathrm{a}=\text { Konstanta } \\
& \beta=\text { Koefisien regresi } \\
& \mathrm{Y}=\text { Kepuasan Kerja } \\
& \mathrm{e}=\text { Error } \\
& \mathrm{X}=\text { Kedisiplinan }
\end{aligned}
$$

\section{F. Uji Model}

Uji model data dalam penelitian ini menggunakan:

Koefisien determinasi digunakan untuk mengetahui besarnya persentase goodness of fit dari variabel independent terhadap variabel dependent (Singgih Santoso, 2000).

\section{G. Uji Hipotesis}

Uji hipotesis menggunakan uji t dengan model regresi linier berganda yaitu untuk mengidentifikasi pengaruh kedisiplinan terhadap kepuasan kerja pegawai pada Politeknik Ilmu Pelayaran Semarang dengan menggunakan SPSS (Singgih Santoso, 2000). Adapun kriteria hipotesis diterima bila taraf signifikan $(\alpha)<0,05$

\section{HASIL PENELITIAN DAN PEMBAHASAN}

\section{A. Analisis Regresi Berganda}

Tabel Hasil Regresi Pengaruh Kedisiplinan (X) Terhadap Kepuasan Kerja (Y)

\begin{tabular}{llcccccc}
\hline \multirow{2}{*}{ No } & \multirow{2}{*}{ Hubungan Variabel } & \multicolumn{6}{c}{ Model Regresi } \\
& $\mathrm{R}^{2}$ & Sig. & $\beta$ & $\mathrm{t}$ & Sig. & Ket \\
\hline 1 & $\begin{array}{l}\text { Kedisiplinan } \\
\text { terhadap kepuasan } \\
\text { kerja }\end{array}$ & 0,422 & 0,000 & 0,138 & 2,141 & 0,000 & Pengaruh \\
& & & & & & Positif \\
\hline
\end{tabular}

Sumber : Data primer yang diolah, 2015 
Dilihat dari tabel di atas dihasilkan persamaan regresi sebagai berikut : $\mathbf{Y}=$ 0,138 X. Berdasarkan persamaan di atas terlihat bahwa kedisiplinan mempunyai pengaruh positif terhadap kepuasan kerja dengan nilai koefisien regresi kedisiplinan $=$ 0,138 .

Hasil koefisien determinasi diperoleh angka koefisien Adjusted $R$ Square sebesar 0,422 . Hal ini berarti bahwa kepuasan kerja sebesar 42,2\% dapat dijelaskan oleh karakteristik pekerjaan dan kedisiplinan sedangkan sisanya $57,8 \%$ dijelaskan oleh sebab-sebab yang lain di luar variabel karakteristik pekerjaan dan kedisiplinan.

\section{B. Pengujian Hipotesis}

Pengaruh kedisiplinan terhadap kepuasan kerja dapat disajikan dalam tabel di atas:

Kedisiplinan (X) menghasilkan t hitung 2,141 dan tingkat signifikan $0,034<0,05$ sehingga secara parsial (individu) terdapat pengaruh positif dan signifikan terhadap kepuasan kerja $(\mathrm{Y})$. Dengan demikian hipotesis $(\mathrm{H})$ "Kedisiplinan berpengaruh terhadap kepuasan kerja" dapat diterima.

\section{Pembahasan}

Penelitian yang dilakukan untuk mengetahui pengaruh kedisiplinan terhadap kepuasan kerja pegawai Politeknik Ilmu Pelayaran Semarang adalah sebagai berikut : Kedisiplinan (X) menghasilkan t hitung 2,141 dan tingkat signifikan $0,034<0,05$ sehingga secara parsial (individu) terdapat pengaruh positif dan signifikan terhadap kepuasan kerja $\left(\mathrm{Y}_{1}\right)$. Dengan demikian hipotesis $(\mathrm{H})$ "Kedisiplinan berpengaruh terhadap kepuasan kerja" dapat diterima.

Hasil penelitian ini juga didukung oleh penelitian sebelumnya yang dilakukan oleh Siti Surasri dan Sunarti (2008) menghasilkan kedisiplinan berpengaruh positif dan signifikan terhadap kepuasan kerja. Pegawai akan bisa menerima tindakan pendisiplinan bila pendisiplinan tersebut terasa adil dan beralasan serta diterapkan secara konsisten dan berlaku sama untuk semua orang. Hal tersebut akan dapat menciptakan kepuasan kerja pegawai.

\section{Implementasi Manajerial}

Berdasarkan dari hasil penelitian mengenai pengaruh kedisiplinan terhadap kepuasan kerja pegawai Politeknik Ilmu Pelayaran Semarang, maka dapat ditindaklanjuti oleh pihak manajemen melalui indikator-indikatornya antara lain sebagai berikut :

Kedisiplinan juga mempunyai pengaruh terhadap kepuasan kerja oleh sebab itu pihak kepegawaian Politeknik Ilmu Pelayaran Semarang juga perlu meningkatkan lagi faktor kedisiplinan dengan melihat indikator yang masih kurang menurut jawaban responden yaitu pegawai kurang memelihara barang-barang milik negara dengan baik serta pegawai sering meninggalkan pekerjaan pada jam bekerja.

\section{PENUTUP}

\section{Kesimpulan}

Berdasarkan analisis data mengenai pengaruh kedisiplinan terhadap kepuasan kerja pegawai Politeknik Ilmu Pelayaran Semarang dapat diambil kesimpulan sebagai berikut:

a. Kedisiplinan berpengaruh terhadap kepuasan kerja;

b. Kedisiplinan pekerjaan berpengaruh terhadap kepuasan kerja;

c. Kedisiplinan berpengaruh terhadap kinerja karyawan;

d. Kedisiplinan berpengaruh terhadap absensi kehadiran.

\section{Implikasi}

Berdasarkan dari hasil penelitian mengenai pengaruh kedisiplinan terhadap kepuasan kerja pegawai Politeknik Ilmu Pelayaran Semarang, maka dapat ditindak lanjuti oleh pihak manajemen melalui indikator-indikatornya antara lain sebagai berikut:

Kedisiplinan juga mempunyai pengaruh terhadap kepuasan kerja oleh sebab itu pihak kepegawaian Politeknik Ilmu Pelayaran Semarang juga perlu meningkatkan lagi faktor kedisiplinan dengan melihat indikator yang masih kurang menurut jawaban responden yaitu: 
Janny Adriani Djari ${ }^{\mathrm{a}}$, Firdaus Sitepu ${ }^{\mathrm{b}}$

a. Pegawai kurang memelihara barang-barang milik negara dengan baik.

b. Pegawai sering meninggalkan pekerjaan pada jam bekerja.

c. Pegawai sering terlambat dalam kehadiran masuk kerja.

d. Pegawai kurang kesadaran dalam membuat sasaran kinerja pegawai.

\section{Keterbatasan Penelitian}

Keterbatasan yang terdapat pada penelitian ini antara lain :

a. Hasil koefisien determinasi diperoleh angka koefisien Adjusted $R$ Square sebesar 0,422. Hal ini berarti bahwa kepuasan kerja sebesar $42,2 \%$ dapat dijelaskan oleh karakteristik pekerjaan dan kedisiplinan sedangkan sisanya $57,8 \%$ dijelaskan oleh sebab-sebab yang lain di luar variabel kedisiplinan seperti kepemimpinan, kompensasi dan promosi jabatan.

b. Sampel dapat ditambah tidak hanya 142 responden saja.

\section{Rekomendasi}

Berdasarkan dari hasil penelitian mengenai pengaruh kedisiplinan terhadap kepuasan kerja pegawai Politeknik Ilmu Pelayaran Semarang, maka dapat dikemukakan beberapa saran:

a. Variabel kedisiplinan mempunyai pengaruh terhadap kepuasan kerja pegawai Politeknik Ilmu Pelayaran Semarang, oleh sebab itu pihak Politeknik Ilmu Pelayaran Semarang perlu meningkatkan lagi kedisiplinan pegawai dengan memperbaiki indikator dilihat dari jawaban responden yang masih rendah antara lain pegawai bekerja lebih diutamakan untuk kepentingan negara dari pada kepentingan sendiri, seseorang atau golongan. Pegawai untuk menggunakan dan memelihara barangbarang milik negara dengan baik serta peningkatan kejujuran pada pegawai atas tugas yang dikerjakannya.

b. Memasukkan variabel-variabel lain yang mempengaruhi kepuasan kerja selain variabel di atas seperti kompensasi, kepemimpinan dan lingkungan kerja.

\section{DAFTAR PUSTAKA}

Anjani. 2006. Pengaruh Motivasi dan Kedisiplinan Terhadap Kinerja Karyawan Melalui Komitmen Organisasi Sebagai Variabel Mediasi (Studi Kasus Pada PT. Tanjung Pinang Lampung), Jurnal Telaah Manajemen Vol. 2 Edisi 4 Tahun 2006

Aranya, N dan K. Ferris. 1993. Role of Leadership in The Employee With Dralwal Process: A Constructive Replication, Journal of Applied Psychology, 70, 777 - 781

Chan, Su-Chao, Ming-Shing Lee. 2006. Relationship Among Personality Traits, Job Characteristics, Job Satisfaction and Organizational Commitement, An Empirical Studi in Taiwan, Journal The Business

Ebura, Victor Obule, et al. 2012. Influence of Staff Discipline and Attitude To Work On Job Satisfaction Lecturers in Tertiary Institutions in Cross River State, Journal Public Policy and Administration Research, Vol 2 No. 3, 2012

Hadi, Sutrisno. 2001. Metode Penelitian Riset. Yogyakarta: Yayasan Penerbit Fakultas Biologi UGM

Handoko, T. Hani. 1998. Manajemen Personalia dan Sumber Daya Manusia. Edisi 2. Yogyakarta : BPFE

Heidjrachman dan Husnan. 2002. Manajemen Sumber Daya Manusia. Jakarta: Bima Aksara

Luthan, Fred. 1995. Organizational Behavior. Seventh Edition. New Jersey: Prentice Hall 
Merriyanti. 2001. Hubungan Mutu Interaksi Atasan Bawahan Terhadap Intensi Turover. Yogyakarta: Fakultas Psikologi, Universitas Gadjah Mada

Pestari, Puji. 2009. Pengaruh Motivasi dan Disiplin Kerja Terhadap Kepuasan Kerja di Kantor Dinas Pendidikan Jawa Timur, Jurnal Manajemen SDM Vol. XIII Edisi 1 Tahun 2009

Prabu, Anwar. 2000. Manajemen Sumber Daya Manusia. Yogyakarta: Andi Offset

Santoso, Singgih. 2000. Buku Latihan SPSS Statistik Parametrik. Edisi Pertama. Jakarta : PT. Elex Media Komputindo

Sari, Indah Pratita. 2008. Analisis Pengaruh Pengembangan Karir, Kepuasan Kerja Terhadap Kinerja Pagawai Dengan Mediasi Komitmen Organisasional, Jurnal Manajemen SDM Vol. XI Edisi 2 Tahun 2008
Setyawan, Didik. 2009. Pengaruh Kepuasan Kerja Terhadap Kinerja Karyawan Dengan Komitmen Organisasional Sebagai Variabel Intervening dan Pengaruh Etika Kerja Terhadap Kinerja Karyawan (Studi Kasus Pada Badan Rumah Sakit Umum Daerah Sukoharjo), Jurnal Manajemen Vol. 1 Edisi 2 Tahun 2009

Staw B.M. 1991. Psychology Dimensions of Organizational Behavior. New York: Oxford, Macmillan Publishing Company, Inc

Stepen, Robbins. 2006. Perilaku Organisasi, Konsep, Kontroversi dan Aplikasi. Edisi Bahasa Indonesia Jilid I. Jakarta: Prenhallindo

Supranto, J. 1997. Pengukuran Tingkat Kepuasan. Jakarta: Erlangga

William S.J \& Hazer J.W. 1996. Personnel Management ad Human Recourse. Tokyo: McGraw-Hill Kogakusha, Ltd 